\title{
Research on Investment Strategy of Education
}

\author{
Yu Rong Guo ${ }^{1, \text { a }}$ \\ ${ }^{1}$ School of North China Electric Power University, 071000, China; \\ a490133104@qq.com
}

Keywords: ROI, Investment Amount ,Investment Return ,AHP.

\begin{abstract}
The paper aims at the problem of the optimal investment model of Foundation Goodgrant in the international mathematical modeling competition of the United States in 2016.This paper constructs a model to calculate the ROI and determine the investment strategy .so,we builds a model solving investment amount and combine the AHP model solving investment return.

\section{Introduction}

The Goodgrant Foundation is a charitable organization that wants to help improve education performance of undergraduates attending colleges and universities in the United States.To do this ,the foundation intends to donate a total of US100 million to an appropriate group of schools per year ,for five years ,starting July 2016.This paper develops a model to determine an optimal investment strategy that identifies the schools, the investment amount per school, the return on that investment, and the time duration that the organization's money should be provided to have the highest likelihood of producing a strong positive effect on student performance.
\end{abstract}

\section{The Model}

\subsection{Investment Amount Solving}

First ,we makes some independent assumptions, each of which is properly justified.

- Based on the element called LOCALE in the data file, we support them different amount of money for students in different locations. The amount we support shows below.

- Support LOCALE_11 and LOCALE_21 for \$5,000.

- Support LOCALE_12 and LOCALE_22 for $\$ 4,500$.

- Support LOCALE_13 and LOCALE_23 for $\$ 4,000$.

- Support LOCALE_31, LOCALE_32, LOCALE_33,LOCALE_41,LOCALE_42 and LOCALE_43 for $\$ 3,000$.

- A student can get Pell Grant for \$3,000. Actually, a student can gain up to \$5,500.To simplify the problem, we set up that a student can get Pell Grant for \$3,000.

- A student can get Federal Grant for \$3,000 and Federal Grant contains Federal Perkins Loan and Federal Stafford Loan. The highest application amount of Federal Grant is same as Pell Grant. For the case now, we ignore the influence of Federal Plus Loan which provided for parents.

So,the net price is entirely dependent on four parts including grant, loan, foundation and work-study.we can define that

In this equation,

$$
P_{\text {total }}=P-P_{1}-P_{2}-P_{3}
$$

- $P_{\text {total }}$ means the investment amount of all students per year.

- $P$ means the net price of all students per year.

- $P_{1}$ means the money got from full time job of all students per year. 
- $P_{2}$ means the Pell Grant of all students per year.

- $P_{3}$ means the Federal Grant of all students per year.

Then we can set up the following equations:

$$
\begin{aligned}
& P=N \cdot S \\
& P_{1}=N \cdot \omega_{1} \cdot \gamma_{1}+N \cdot \frac{\omega_{1}}{2} \cdot\left(1-\gamma_{1}\right) \\
& P_{2}=N \cdot \omega_{2} \cdot \gamma_{2} \\
& P_{3}=N \cdot \omega_{3} \cdot \gamma_{3} \\
& P_{\text {total }}=N \cdot \omega
\end{aligned}
$$

In this equation,

- $\omega$ means the investment amount of a student per year.

- $\omega_{1}$ means the money got from full time job of a students per year and $\gamma_{2}$ means the ratio of students who has a full time job.

- $\omega_{2}$ means the Pell Grant of a students per year and $\gamma_{2}$ means the radio of students who has the Pell Grant.

- $\omega_{3}$ means the Federal Grant of a students per year and $\gamma_{3}$ means the radio of students who has the Federal Grant.

- $\quad N$ means the total number of students.

- $\quad S$ net price

Additionally, the correlation analysis shows that $\omega_{1}$ is related to the LOCALE, so the paper uses this relation to determine $\omega_{1}$.Then, it can be consolidated into one equation:

$$
\omega=S-0.5 \cdot \omega_{1} \cdot\left(1+\gamma_{1}\right)-\omega_{2} \cdot \gamma_{2}-\omega_{3} \cdot \gamma_{3}
$$

\subsection{Investment Return Solving}

On the basis of data document above, we can draw up academic, degree type, earnings and repayment as return factors which have a close relation on returns.

According to Hierarchical structure model, make a comparative judgment on the relative importance of the elements in a hierarchy and score. Then, it can construct the judgment matrix $B=\left(b_{i j}\right)$, and we know that

$$
b_{i j}=b_{i k} \cdot b_{i j}
$$

Firstly, calculate each row of elements of the judgment matrix. We obtain

$$
M_{i}=\prod_{j=1}^{n} b_{i j} \quad i=1,2, \cdots, n
$$

Secondly, calculate the n-th root of $M_{i}$ :

$$
\overline{W_{i}}=\sqrt[n]{M_{i}}
$$

Where $\overline{W_{i}}$ denotes the he n-th root of $M_{i}$.

Then, normalize the $\overline{W_{i}}=\left[\overline{W_{1}}, \overline{W_{2}}, \cdots, \overline{W_{n}}\right]^{T}$ as follows:

The $\overline{W_{i}}$ is the eigenvector we want to obtain.

$$
W_{i}=\frac{\overline{W_{1}}}{\sum_{i=1}^{n} \overline{W_{i}}}
$$

Finally, calculate the maximum of eigenvalue $\lambda_{\max }$ in the judgment matrix. 


$$
\lambda_{\max }=\sum_{i=1}^{n} \frac{(B W)_{i}}{n W_{i}}
$$

Now, calculate the indicator of consistency as follows:

$$
C I=\frac{\lambda_{\max }-n}{n-1}
$$

The higher consistency degree of judgment matrix, the lower number of $C I$. If $C I \neq 0$, we need to calculate the ratio of consistency:

$$
C R=\frac{C I}{R I}
$$

Finally we should quantify the investment return. We use $G$ to denote grade.

$$
G=\sum_{i=1}^{4} C W_{i} \cdot \sum_{j=1}^{m i} B W_{j} \cdot F_{j}
$$

Where $C W_{i}$ denotes the weigh of $i^{\text {th }}$ criteria level factor, $B W_{i}$ denotes the weigh of $j^{\text {th }}$ secondary criteria level factor and $F_{j}$ denotes the $j^{\text {th }}$ secondary criteria level factor.

\subsection{Result}

AHP use the following scaling method to do importance scale. This kind of method can overcome some problems. Because some factors can't be measured and counted without a scale. According to the importance scale, we can obtain our judgment matrix:

$$
B=\left[\begin{array}{llll}
1 & 1 & \frac{1}{7} & \frac{1}{5} \\
1 & 1 & \frac{1}{5} & \frac{1}{3} \\
7 & 5 & 1 & 3 \\
5 & 3 & \frac{1}{3} & 1
\end{array}\right]
$$

Bring the matrix into calculating, we can obtain the weight vector of criteria level:

$$
C W=\left[\begin{array}{llll}
0.0728 & 0.0895 & 0.5706 & 0.2670
\end{array}\right]
$$

Besides, $C I=0.0273, C R=0.0304$.

Next, we can also obtain the weight vector is alternatives level:

$$
\begin{aligned}
& B W_{2}=\left[\begin{array}{llll}
0.5558 & 0.2589 & 0.1364 & 0.0489
\end{array}\right] \\
& B W_{3}=\left[\begin{array}{ll}
0.5 & 0.5
\end{array}\right]
\end{aligned}
$$

And we can rank the institutions using the grades we obtain and we still can get the weight of factors.After solving the investment amount and investment return, we use $G$ to represent the investment amount and $\omega \cdot t$ to represent the investment return, than we obtain

$$
R O I=\frac{G}{\omega \cdot t}
$$

The achievements of investment in education won't emerge in a short time, so we need a time variable to define ROI. We can use this equation to calculate returns on investment.

\section{Conclusion}

The paper uses the method to determine the weights of factors and calculate the ROI of each school. Then, the Goodgrant Foundation can invest the schools which have the higher ROI.And,we 
can identify the schools, the investment amount per school, the return on that investment, and the time duration that the organization's money should be provided to have the highest likelihood of producing a strong positive effect on student performance.

\section{References}

[1] Su yijuan. Multiple imputation method for missing values by gray relation analysis. Computer Engineering and Applications, 2009, 45(15): 169-172.

[2]China Industry Research Network. http://www.chinairn.com/news/20140217/134828294.html 